\title{
Ground Water and Surface Water as One Resource: Connectivity and Interaction
}

\author{
C. N. Ezugwu ${ }^{1}$, S. Apeh ${ }^{2}$ \\ ${ }^{1}$ Department of Civil Engineering, Federal University, Ndufu Alike, Ikwo, Nigeria. \\ ${ }^{2}$ Department of Civil Engineering, Federal Polytechnic, Idah, Nigeria
}

\begin{abstract}
This discussion paper presents an overview of current understanding of ground water and surface water in terms of quantity and quality, their interaction and connectivity. In the past, groundwater and surface water were managed as if they are separate entities. This led to double accounting by water managers resulting to unrealistic water budgets and general poor management structure of this natural resource. The connectivity and interactions of ground water and surface water were analyzed and found to change with different topography. Understanding the interaction of groundwater and surface water is essential to water managers and water scientists towards provision of cost effective and sustainable water management structure.
\end{abstract}

Keywords: connectivity, ground water, interaction, surface water, water managers.

\section{Introduction}

In the past, management of water resources has focused on surface water or groundwater as if they were separate entities. As development of land and water resources increases, it is apparent that development of either of these resources affects the quantity and quality of the other. Nearly all surface water features (streams, lakes, rivers, reservoirs, wetlands, and estuaries) interact with ground water. These interactions take many forms. In many situations, surface water bodies gain water and solutes from ground water systems and in others the surface water body is a source of groundwater recharge and causes changes in groundwater quality and quantity. As a result, withdrawal of water from streams can deplete groundwater or conversely, pumpage of groundwater can deplete water in streams, lakes, or wetlands. Pollution of surface water can cause degradation of groundwater quality and conversely pollution of ground water can degrade surface water. Thus, effective land and water management requires a clear understanding of the linkages between groundwater and surface water as it applies to any given hydrologic setting.

Understanding the interconnections of groundwater and surface water is fundamental to development of effective water-resource management and policy. As the world's concerns over water resources and the environment increase, the importance of considering groundwater and surface water as a single resources has become increasingly evident. Issues related to water supply, water quality and quantity, degradation of aquatic environments are reported on frequently. The interaction of groundwater and surface water has been shown to be a significant concern in many of these issues. For instance, contaminated aquifers that discharge to streams can result in long-term contamination of surface water; conversely streams can be a major source of contamination to aquifers. Surface water commonly is hydraulically connected to ground water, but the interactions are difficult to observe and measure and commonly have been ignored in water management considerations and policies. The interaction between surface water and groundwater is hidden from view, and historically we have tended to manage the two resources separately. As a result, we have often double accounted and double allocated the same resource- once as surface water and a second time as groundwater-even through physically we are dealing with the same parcel of water. We have often not recognized this interaction because ground water moves very slowly beneath the surface. The time taken for groundwater extractions to influence stream flows may range from days to many decades. Thus the interaction we become aware of today might be the legacy of actions taken many years back.

As global exploitation of both stream water and groundwater increases, it is becoming more evident that managers need to develop an awareness of the linkages between these two systems, the roles that these linkages play in maintaining water quality, and how human activities may impair them. The impact of human activities on surface stream habitant has been extensively studied throughout the world [1][2][3][4], and this scientific information is now the basis for many stream restoration efforts[5][6].

\subsection{The Concept of Sustainability}

The concept of what is "Sustainable" for groundwater systems differ from surface water due to the differences in water availability and the critical variable, time. The time lag between groundwater pumping and a measurable impact at a distance (or to a surface water body) can range from days to decades. Consequently, basin plan strategies considering surface water and groundwater usage and sustainability need to consider 
multiple planning periods. Policies and management designed for sustainability over 10 years are unlikely to be suitable to intergenerational suitability of time periods between 50 and 100 years[7]. Short time options to manage connectivity (such as distances and zones) are useful for short time protection of surface flows and impacts on streamflow. However, long-term management options are required in many systems if intergenerational equity, equity between surface water and ground water users, and catchment water sustainability are the primary objectives for management. Long term sustainable management is likely to involve consideration of the long-term access arrangements and rights of license holders (both surface and groundwater).

- The Interaction of Ground Water and Surface Water

We know that the hydrologic cycle describes the continuous movement of water above, on, and below the surface of the Earth.

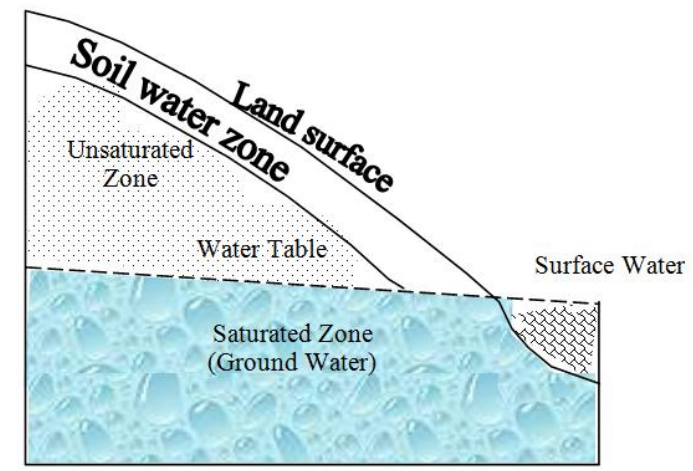

Figure 1. Zones of water beneath the land surface.

Water beneath the land surface occurs in two principal zones, the unsaturated and the saturated zones (See Figure 1). In the unsaturated zone, the voids that is, the spaces between grains of gravel, sand, silt, clay and cracks within rocks and soil - contain both air and water. Although a considerable amount of water can be present in the unsaturated zone, this water cannot be pumped by wells because it is held too tightly by capillarity forces. The upper part of the unsaturated zone is the soil-water zone. The soil water zone is crisscrossed by roots, voids left by decayed roots, and animal and worm burrows, which enhance the infiltration of precipitation into the soil zone. Soil water is used by plants in life functions and transpiration, but it also can evaporate directly to the atmosphere.

In contrast to the unsaturated zone, the voids in the saturated zone are completely filled with water. Water in the saturated zone is referred to as ground water. The upper surface of the saturated zone is referred to as the water table. Below the water table, the water pressure is great enough to allow water to enter wells, thus permitting the groundwater to be withdrawn for use. A well is constructed by inserting a pipe into a drilled hole; a screen is attached generally at its base to prevent earth materials from entering the pipe through the screen along with the water pumped. The depth of the water table is highly variable and can range from zero, when it is at land surface, to hundreds or even thousands of feet in some types of landscapes. Normally, the dept to the water table is small near permanent bodies of surface water such as streams, lakes and wetlands. Characteristically, the configuration of the water table varies seasonally and from year to year because ground water recharge, which is the accretion of water to the upper surface of the saturated zone, is related to the wide variation in the quality, distribution, and timing of precipitation. The depth to the water table can be determined by installing wells that penetrate the top of the saturated zone just for enough to hold standing water.

\section{Groundwater \& Surface Water Connectivity: A Review}

Surface water and groundwater managers are well aware of the issue of interconnection of surface water and groundwater in different water basins, including the ones in Nigeria. However, the connectivity of groundwater and surface water systems involves a complex interplay of many variables. These variables are multi-dimensional (involving three spatial dimensions and the dimension of time). Most of these variables are also heterogeneous (not uniform). The complex nature of connectivity is therefore very difficult to define technically, difficult to measure, and even very difficult to manage. Moreover, management also needs to consider the equity and sharing of water allocations between the various extractive users and the environment itself. The impact of time is one of the key variables to understand or appreciate when managing surface and groundwater connectivity issues. Time impacts apply to all types of connected and disconnected systems. There exists seasonal, short term and long term impacts. Sustainability and impacts therefore need to be considered in reference to a time frame, be it seasonal, ten year plan, or longer term intergenerational timeframes. 


\subsection{Fundamentals of Connected Systems}

Surface water and groundwater components of the water cycle are emphasized in the hydrological cycle (See Figure 2). The basis of the hydrological cycle is a continuous movement of water; and the surface water-ground water interaction aspect is one of the least understood aspects of the hydrological cycle [8]. Given a long enough period of time, the surface water and groundwater units within larger catchments are fully connected [8].

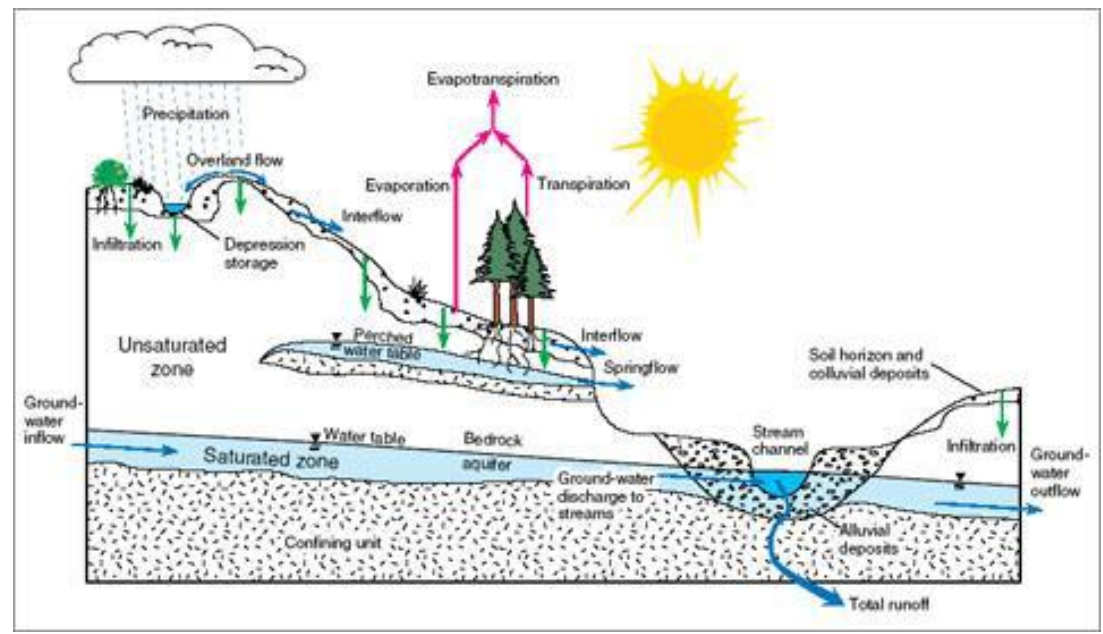

Source: [9].

Figure 2. Water cycle emphasizing ground water components

At the catchment scale, the sum of all water cycle recharge will equal the sum of all discharge. Simplistically, if groundwater is extracted, storage initially begins to deplete. Storage depletion in connected systems is eventually followed by impacts to surface water systems (via increased losses from surface water and/or decreased discharge back to surface water). These impacts will continue to increase until a new equilibrium is established. One of the primary management issues within a catchment is the length of time it takes for groundwater pumping impacts to reach the connected surface water system and the time until a new equilibrium is established.

The water cycle, which includes both surface and groundwater, is a dynamic and interconnected system. In many instances, surface water, which includes water flowing through our creeks, streams, and rivers, has its origins below the surface. More research is needed to completely understand the degree of interconnectivity of our water resources. However, in some areas, the fact that our surface water resources are highly dependent on the underlying aquifers (and vice versa) is well understood and documented. Groundwater and surface water are essentially one resource, physically connected by the hydrological cycle. Although water law and water policy often consider them as separate resources, ground water and surface water are functionally inter-dependent. Groundwater and surface water interactions are controlled by their hydraulic connection.

\subsubsection{Interaction of Groundwater \& Streams}

\section{- Hydraulically Connected Systems}

Water is known conceptually to flow from region of higher elevation to lower elevation. If the ground water table is in physical contact with the stream bed, it is a hydraulically connected system. The exchange of water between groundwater system and a stream is controlled by the difference in elevation between groundwater table and the water level in the stream.

\section{$>$ Gaining streams}

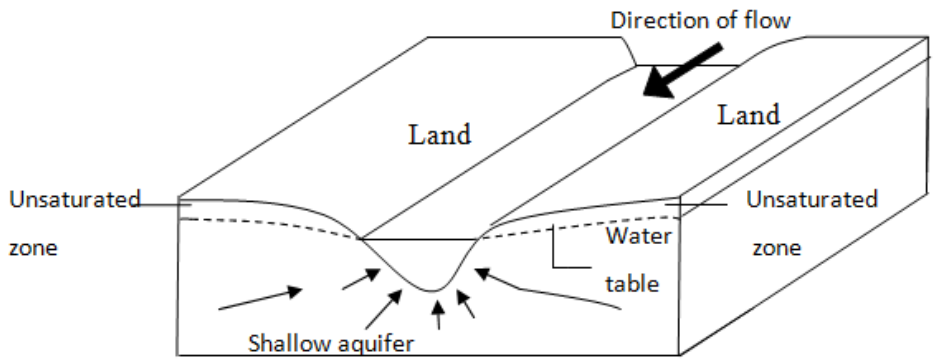

Figure 3. Gaining stream 
In a gaining stream, groundwater levels are above the water level in the stream [10]. Under these conditions, the groundwater system discharges water to the stream, increasing flow in the stream. Under natural conditions, prior to the pumping of groundwater from wells, streams are the primary discharge outlet for groundwater; rainfall percolates into the groundwater system, eventually discharging to streams. Groundwater discharge to streams provides the baseflow of streams and is often a primary component of the total streamflow. When groundwater wells are developed, pumping captures water that would otherwise discharge to streams, which decrease the baseflow to the streams. This decrease in groundwater discharge to streams, caused by pumping, is called stream depletion. Groundwater can also discharge to lakes, wetlands and other similar habitat in low-lying areas when groundwater is near the surface. Like streams, groundwater discharge to these surface water features is reduced by groundwater pumping.

\section{Losing streams}

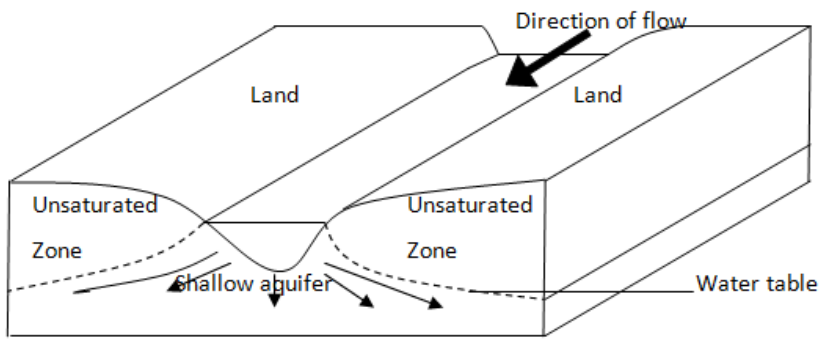

Figure 4: Losing streams

However, in losing streams, groundwater levels are lower than water levels in the stream, and the water from the stream recharges the groundwater system. Several different conditions can cause a stream to be a losing stream. For instance, if groundwater pumping is sufficient to lower regional groundwater levels (i.e. the water table lowered) or if a well is located very near a stream, groundwater levels can drop below stream levels, including groundwater recharge from streams. These conditions can persist for months or years. The loss of water from streamflow, caused by pumping is also called stream depletion. Natural conditions, such as flood events, can also create losing stream conditions. During flood events, stream levels can temporarily rise above groundwater levels, causing streams to recharge into the groundwater system adjacent to the stream. However, when the water levels in the stream return to normal, this water will drain back into the stream. This rapid exchange of water between the stream and the groundwater system during flood events is not called stream depletion.

- Hydraulically Disconnected Systems

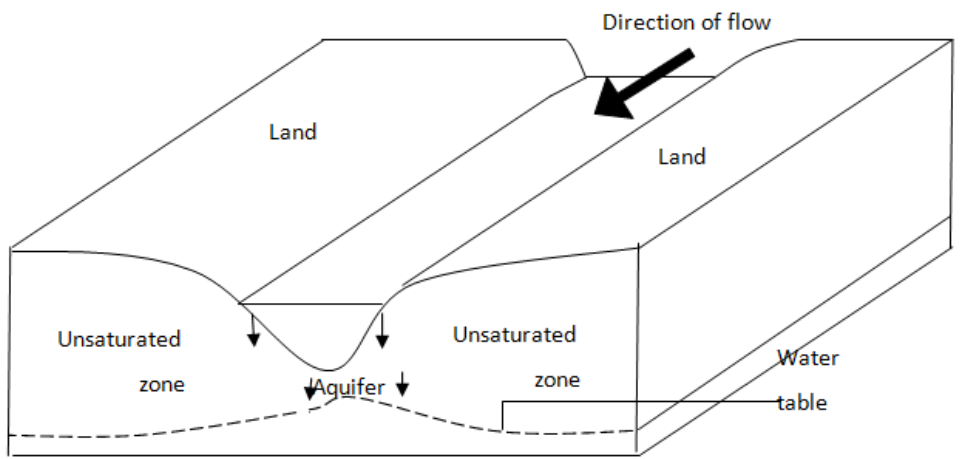

Figure 5: Disconnected Stream

If a stream is separated from the groundwater table by an unsaturated zone, it is a hydraulically "disconnected" system. In disconnected systems, although groundwater pumping does not affect streams, streams do affect groundwater through streambed seepage that recharges the groundwater system. Groundwater systems are often disconnected from the streams in arid regions where the water table is very far from the surface due to reduced rainfall and in regions where groundwater pumping has significantly lowered groundwater levels. 
- $\quad$ Bank storage

If stream levels rise higher than adjacent ground water levels, stream water moves into the streambanks as bank storage (See Figure 6). In nearly all streams, a type of interaction between ground water and streams take place at one time or another leading to a rapid rise in stream stage that causes water to move from the stream into the stream banks. This process, termed bank storage, usually is caused by storm precipitation, rapid snowmelt, or release of water from a reservoir upstream. As long as the rise in stage does not affect overtop the stream banks, most of the volume of stream water that enters the stream banks returns to the stream banks within a few days or weeks. The loss of stream water to bank storage and return of this water to the stream within days or weeks tends to reduce flood peaks and later supplement stream flows.

It indicates that the head difference between the river and the aquifer determines the direction of flow. The rate of flow between the river and aquifer will depend on the hydraulic conductivity of the aquifer and the hydraulic conductance of the bed of the river. Figure 5 provides an example of a stream that is connected to the adjoining aquifer through an unsaturated zone; this situation is usually found in arid areas and ground water is controlled by the unsaturated zone hydraulic conductivity [11]. Of importance is the timing of impacts. [12] has shown that it is important to water resources managers whether the impacts from groundwater pumping on a stream occur within an irrigation season, or over a long period. Connectivity will control the timing of groundwater recharge and it will control the timing of changes in discharge from groundwater to the streams due to ground water abstractions. Streams interact with groundwater in three basic ways: stream gain water from inflowing ground water through the streambed (gaining stream), they lose water to ground water by outflows through the streambed (losing stream) or they do both, gaining in some reaches and losing in other reaches.

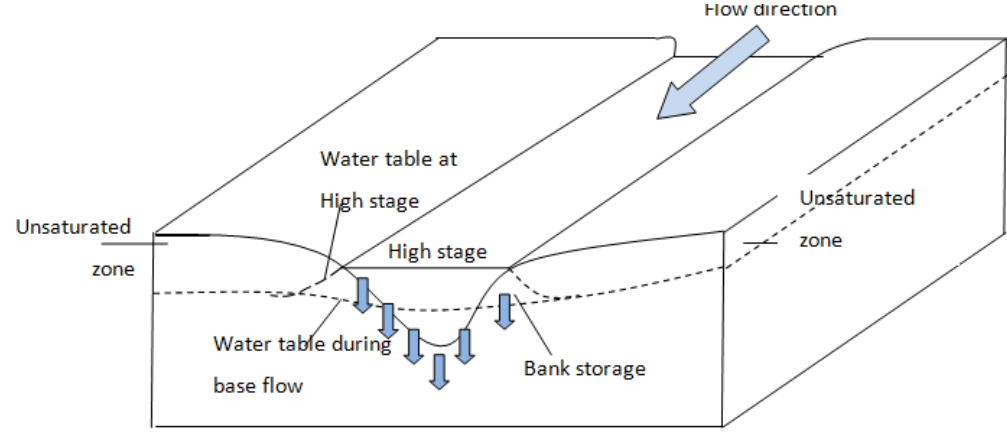

Figure 6: Fluctuating connected/disconnected system

Source: Modified after [13]

\section{Effect Of Human Activities On The Interaction Of Ground Water And Surface Water}

This is evident in water supply and aquatic environment. Mixing of groundwater with surface water can have major effects on aquatic environments if factors such as acidly, temperature, and dissolved oxygen are altered. Thus, changes in the natural interaction of ground water and surface water caused by human activities can potentially have a significant effect on aquatic environments. The distribution, quantity and chemical quality of water resources is commonly affected by human activities. The range of human activities affecting this interaction is broad.

\section{- Development of Agriculture}

Agriculture has been the cause of significant modification of landscapes throughout the world. Agricultural practice of land tillage changes the infiltration and runoff characteristics of the land surface, which affects recharge to ground water, delivery of water and sediment to surface water bodies, and evapotranspiration. These processes, directly or indirectly affect the interaction of ground water and surface. There exists substantial negative effects of agriculture on water resources; and agriculturists have developed measures to alleviate some of the effects. For example, tillage practices have been modified to maximize retention of water in soils and to minimize erosion of soil from the land into surface water bodies. Two activities related to agriculture that are particularly relevant to the interaction of ground water and surface water are irrigation and application of chemical to cropland.

- Urban and Industrial Development

Surface water bodies through point sources contamination affect urban development. Examples of point sources include direct discharges from sewage treatment plants, industrial facilities, and storm water drains. Contaminants in streams can easily affect ground water quality, especially where streams normally seep to ground water, where ground water withdrawals induce seepage from the stream, and where floods cause stream water to become bank storage. Point sources of contamination to ground water can include septic tanks, 
fluid storage tanks, landfills and industrial lagoons. A contaminant that is soluble in water that reaches the water table moves slowly with the ground water and may enter streams also.

- Land Surface Drainage

In flat landscapes, water is found on the land surface. Drainage can be accomplished by constructing open ditches or by burying tile drains beneath the land surface. More efficient runoff caused by drainage systems results in decreased recharge to ground water and greater contribution to flooding and stream flow.

- Modifications to River Valleys

This can be achieved through construction of levees and reservoirs and removal of natural vegetation from land surface. Construction of levees and reservoirs protects an area against flooding. The area having the pool of water recharges the ground water in the vicinity. Destruction of riparian vegetation and wetlands removes the benefits of erosion control and flood mitigation, while altering aquatic habitat and chemical processes that maintain water quality.

- Modifications to the Atmosphere

Chemicals such as sulphate and nitrate can be deposited in the atmosphere. They can cause surface water bodies to be acidic. Concern about the effects of acidic precipitation on aquatic ecosystems has led to research on the interaction of ground water and surface water. This interaction is important to determining the susceptibility of a surface water body to acidic precipitation. The concentration of gases, such as carbon dioxide $\left(\mathrm{CO}_{2}\right)$ and methane $\left(\mathrm{CH}_{4}\right)$, in the atmosphere has a significant effect on the heat budget of the earth's surface and the lower atmosphere. The increase concentration of $\mathrm{CO}_{2}$ in the atmosphere of about $25 \%$ since the late 1700 s generally is thought to be caused by the increase in burning of fossil fuels. This results to global warming of the earth.

\section{Conclusion}

Effective management requires decisions to be based on the best scientific information, and close collaboration between managers is a necessary step in achieving this. Managers must recognize the importance of links between surface water and ground water and incorporate this into their restoration and management plans. Undoubtedly, it has been established that most groundwater and surface water interact. Ground water and surface water are the same resource found in different locations at different times as provided by nature; also due to human activities. They should be managed as one resource, since managing them separately results in double accounting, leading to wrong analysis and unrealistic water budget.

\section{Future Plans}

More research is needed to completely understand the degree of interconnectivity of our water resources in different locations. International aid should be sought to sponsor this research in different locations to study comprehensively these interactions.

\section{References}

[1]. Hynes, H.B.N. (1960). The biology of polluted waters. Liverpool University Press, Liverpool, pp.122.

[2]. Johnson, L.B., Richards, C., Host, G.E., and Arthur, J.W. (1997). Landscape influences on water chemistry in Midwestern stream ecosystems. Freshwater Biology 37:193-208.

[3]. Townsend, C.R., Arbuckle, C.J., Crowl, T.A. and Scarsbrook, M.R. (1997). The relationship between land use and physicochemistry, food resources and macroinvertebrate communities in tributaries of the Taieri River, New Zealand: A hierarchically scaled approach. Freshwater Biology 37:177-191.

[4]. Parker, J. T.C., Fossum, K. D. and Ingersoll, T. C. (2000). Chemical characteristics of urban storm water sediments and implications for environmental management, Maricopa country, Arizona. Environmental management, 26:99-115.

[5]. Stanford, J.A., Ward, J.V., Liss, W.J., Frissell, C.A., Williams, R.N., Lichatowich, J.A. and Coutant, C.C. (1996). A general protocol of restoration of regulated rivers. Regulated Rivers: Research and Management 12:391-413.

[6]. Wissmar, R.C., and Beschta, R.L. (1998). Restoration and management of riparian ecosystems: A catchment perspective. Freshwater Biology 40:571-585.

[7]. Kalf, R. P and Woolley, D. R. (2006). Applicability and methodology of determining sustainable yield in groundwater systems. Hydrogeology Journal 13:295-312.

[8]. Evans, R. (2007). The Impact of ground water use on Australia's rivers - Technical Report. Land and Water, Australia

[9]. USGS Website

[10]. United States Geological Survey (1998). Circular 1139.

[11]. SKM (2011).National framework for integrated management of connected groundwater and surface water systems, Waterlines report, National Water Commission, Canberra.

[12]. Bredehoeft, J.D. (2011). Hydrologic Trade-Offs in Conjunctive Use Management. Groundwater Vol 49, No 4, pp. 468-475.

[13]. Winter, T.C., Judson, W.H., Franke, O. L. and Alley, W.M. (1998). Ground water and surface water: a single resource. Circular 1139, U.S. Geological Survey, Denver. 